\title{
Use of the Cardiovascular Polypill in Secondary Prevention of Cerebrovascular Disease: A Real-Life Tertiary Hospital Cohort Study of 104 Patients
}

\author{
Victoria Ros-Castelló Elena Natera-Villalba Ana Gómez-López \\ Arantxa Sánchez-Sánchez Juan Luis Chico-García \\ Sebastian García-Madrona Rocio Vera-Lechuga \\ Consuelo Matute-Lozano Alicia de Felipe Mimbrera \\ Antonio Cruz-Culebras Araceli Alonso-Canovas Jaime Masjuan
}

Servicio de Neurología, Hospital Universitario Ramón y Cajal, Departamento de Medicina, Facultad de Medicina, Universidad de Alcalá, IRYCIS, Madrid, Spain

Keywords

Adherence $\cdot$ Stroke $\cdot$ Polypill $\cdot$ Prevention

\begin{abstract}
Background: The use of the cardiovascular polypill, a fixed-dose combination treatment, is conceived to improve adherence. However, randomized controlled trials (RCTs) may overestimate it. Studies focusing on cerebrovascular disease and real-life efficacy compared with conventional treatment are lacking. Methods: This is a retrospective, hospital-based cohort study of acute ischaemic stroke patients who were prescribed a polypill (aspirin $100 \mathrm{mg}$, atorvastatin 20/40 mg, ramipril 2.5/5/10 mg) versus conventional treatment (aspirin $100 \mathrm{mg}$ and other blood pressure/lipid-lowering agents) in secondary prevention (2017-2018). Clinical records were reviewed 90 days after discharge for stroke recurrence, vascular risk factor control, and safety. Adherence was assessed using the adapted Morisky-Green scale. Results: A total of 104 patients were included (61\% male; mean age $69.7 \pm 13.9$ years); 54 were treated with the polypill and 50 with conventional treatment. No baseline differences in clinical or demographic variables were detected. No recurrences were registered in the polypill group, compared to 1 recurrence in the conventional treatment group. A significant reduction of systolic blood pressure (SBP) was achieved in the polypill group $(12.1 \mathrm{~mm} \mathrm{Hg})$ compared to the conventional treatment group $(6.8 \mathrm{~mm} \mathrm{Hg})(p=0.002)$. No significant differences were detected regarding the goal of $L D L$ cholesterol $\leq 70 \mathrm{mg} / \mathrm{dL}$ (41 vs. $44 \%$ ). The adverse events were mild and their frequency was similar in the two groups ( 9 vs. $2 \%$, ns). Adherence was similarly good in the
\end{abstract}


two groups (93 vs. $88 \%$, ns). Polypill group adherence was similar to that reported in a previous meta-analysis of RCTs (93 vs. 84\%, ns). Conclusion: In our experience, the cardiovascular polypill achieved a higher reduction in SBP levels and was well tolerated. Adherence was similar to that found in the previous literature, which is remarkable given the real-life setting of our study.

\section{Introduction}

Ischaemic stroke is one of the leading causes of death worldwide, and it is associated with high morbidity due to neurologic disability, psychological and social consequences, and risk of recurrence. On average, the risk of recurrence after an ischaemic stroke or transient ischaemic attack is $3-4 \%$. This risk is highest within the first 90 days after the cerebrovascular event, but it varies widely depending on patients' baseline characteristics and the degree of control of vascular risk factors (VRFs) [1,2]. Control of VRFs may be challenging for many reasons, especially low adherence, due to the chronicity of the disease, co-payment costs, high pill burden, or the absence of educational programs addressed to patients and physicians [3]. Adherence to secondary prevention treatment amongst patients with cardiovascular disease has shown to improve outcomes and decrease mortality [4]. One of the strategies for improving adherence is the use of fixed-dose combination treatments or polypills, which have proven useful to control VRFs in several studies [5-16].

In Europe, the first commercialized polypill for secondary cardiovascular prevention contains $100 \mathrm{mg}$ of acetylsalicylic acid (ASA), 20 or $40 \mathrm{mg}$ of atorvastatin, and 2.5, 5 or $10 \mathrm{mg}$ of ramipril. These components have proven effective in reducing mortality from cerebrovascular diseases [14-17]. A consensus document about the use of the cardiovascular polypill developed by neurologists was published [18]. According to the document, the polypill could be used in patients with atherothrombotic stroke, lacunar stroke, and cryptogenic stroke and VRFs either if they had previously taken the three separate components or "de novo" after hospital discharge [18].

Multiple clinical trials have demonstrated that the polypill is effective in reducing VRFs when compared to its separate components, and some studies proved that the polypill significantly increased therapy adherence [5-16]. However, the proportion of patients with cerebrovascular diseases included in those studies was low. Moreover, randomized controlled trials (RCTs) may overestimate adherence. Positive results in reducing blood pressure (BP) and LDL cholesterol (LDLc) levels in a real-life setting study of patients treated with the polypill were recently published, but no conventional treatment group was included [19]. To our knowledge, this is the first real-life cohort study to evaluate cardiovascular polypill effectivity, safety, and adherence in patients with cerebrovascular diseases.

\section{Methods}

Our observational retrospective cohort study was conducted in consecutive patients admitted due to ischaemic stroke to the neurology department of our tertiary university hospital from January 2017 to January 2018. Patients who received treatment with the cardiovascular polypill (ASA $100 \mathrm{mg}$, atorvastatin $20 / 40 \mathrm{mg}$, and ramipril 2.5/5/10 mg) or conventional treatment (ASA $100 \mathrm{mg}$ and other BP-lowering/lipid-lowering agents) in secondary prevention were enrolled. Eligible patients were adult (no upper age limit) and functionally independent before the stroke.

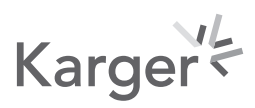


All patients were systematically assessed on discharge and 90 days after the stroke as part of clinical routine at our centre. The doses of ramipril and atorvastatin were decided on based on BP and LDLc levels. The group under conventional treatment received a different treatment for hypertension, which included angiotensin-converting enzyme inhibitors, angiotensin II receptor blockers, beta-blockers, or thiazides. As for LDLc, the patients in the conventional treatment group received atorvastatin or other lipid-lowering agents such as ezetimibe. The decision on whether to start treatment with the polypill or conventional treatment was made by a vascular neurologist consultant. Patients with a preferential indication for the vascular polypill met some of the following criteria: using polymedication, being elderly, having multiple vascular diseases, being young active workers, or having suspicion for poor adherence to treatment [18].

Baseline features, medical history, clinical evaluation, and laboratory tests were obtained from clinical records completed by neurologists. Stroke severity was measured with the National Institutes of Health Stroke Scale (NIHSS) [20]. The aetiology of the stroke was assessed by performing a thorough study, which included supra-aortic and transcranial vessel Doppler or computed tomography angiography, EKG monitorization, and transthoracic echocardiography. The aetiology of the stroke was defined according to the TOAST classification [21]. Patients were eligible for the study if their stroke was atherothrombotic, a lacunar stroke, or a cryptogenic stroke with VRFs.

A clinical assessment was performed 90 days after the stroke at the Cerebrovascular Disease Clinic. LDLc levels were evaluated from blood tests performed within 2 weeks prior to the clinical assessment, and BP levels were assessed. Goals of BP $<140 / 90 \mathrm{~mm} \mathrm{Hg}$ and LDLc $\leq 70 \mathrm{mg} / \mathrm{dL}$ were established according to the prevailing guidelines when the enrollment started [1,22]. Adherence was evaluated using an adaption of the Morisky-Green questionnaire by Val Jiménez [23]. This adapted scale includes four questions: (1) "Some people forget to take their medications, do you do this?" (2) "Some people miss out a dose of their medication or adjust it to suit their own needs, do you do this?" (3) "Some people stop taking their medication when they feel better, do you do this?" and (4) "Some people stop taking their medication when they feel worse, do you do this?" If the answer was negative to every question, the patient was considered to have good adherence. An adaptation of the TSQM-9 questionnaire was used to assess satisfaction in the patients treated with the polypill [24].

The main efficacy outcomes were changes from baseline in BP levels and LDLc levels; the proportion of patients achieving the BP and LDLc goals; and stroke recurrence, safety, and adherence.

Categorical variables are presented as proportions, and continuous variables as mean and standard deviation. The $\chi^{2}$ test was used to compare categorical variables and, and Student's $t$ test for continuous variables. Statistical significance was considered for $p$ values $<0.05$. The analyses were performed using SAS 9.2.

\section{Results}

Data from 104 patients were collected: 54 were treated with the polypill (65\% male; mean age $67.7 \pm 12.8$ years) and 50 with conventional medications (56\% male; mean age $71.7 \pm 14.8$ years) (ns). There were no significant differences regarding VRF distribution. The patients' baseline characteristics are summarized in Table 1.

Regarding treatment upon discharge, the doses and treatments received are summarized in Table 2. In the conventional treatment group, only 1 patient received ramipril. The remaining patients received different BP-lowering agents such as other angiotensinconverting enzyme inhibitors, angiotensin II receptor blockers, beta-blockers, and thiazides.

\section{Karger'}




\section{Cerebrovascular Diseases Extra}

Table 1. Baseline characteristics

\begin{tabular}{l|l}
\hline Cerebrovasc Dis Extra 2020;10:166-173 \\
\hline DOI: 10.1159/000511064 & $\begin{array}{l}\text { @ } 2020 \text { The Author(s). Published by S. Karger AG, Basel } \\
\text { www.karger.com/cee }\end{array}$ \\
\hline
\end{tabular}

Ros-Castelló et al.: Real-Life Study of Cardiovascular Polypill Use

\begin{tabular}{lcc}
\hline & Polypill & $\begin{array}{c}\text { Conventional } \\
\text { treatment }\end{array}$ \\
\hline Patients, $n$ (\%) & $54(100)$ & $50(100)$ \\
Mean age \pm SD, years & $67.7 \pm 12.8$ & $71.7 \pm 14.8$ \\
Male, $n$ (\%) & $35(64.8)$ & $28(56)$ \\
Vascular risk factors, $n$ (\%) & $42(77.8)$ & $32(64)$ \\
$\quad$ Hypertension & $29(53.7)$ & $26(52)$ \\
Hyperlipidaemia & $10(18.5)$ & $16(32)$ \\
Diabetes mellitus & $24(44.4)$ & $22(44)$ \\
Smoking & $1(1.9)$ & $3(6)$ \\
$\quad$ Previous stroke & $1(1.9)$ & $9(18)$ \\
Previous treatment, $n$ (\%) & $34(63)$ & $28(56)$ \\
$\quad$ Antiplatelets & $12(22.2)$ & $18(36)$ \\
$\quad$ BP-lowering agents & & \\
Cholesterol-lowering agents & & \\
\hline
\end{tabular}

SD, standard deviation; BP, blood pressure.

Table 2. Treatment on discharge

\begin{tabular}{|c|c|c|c|}
\hline & Polypill & $\begin{array}{l}\text { Conventional } \\
\text { treatment }\end{array}$ & $p$ value \\
\hline Patients, $n(\%)$ & $54(100)$ & $50(100)$ & \\
\hline \multicolumn{4}{|l|}{ BP-lowering agents, $n(\%)$} \\
\hline Ramipril $2.5 \mathrm{mg}$ & $18(33.3)$ & $1(24)$ & \\
\hline Ramipril 5 mg & $14(25.9)$ & - & \\
\hline Ramipril $10 \mathrm{mg}$ & $22(40.1)$ & - & \\
\hline Other BP-lowering agents & $12(22.2)$ & $44(88)$ & \\
\hline$>1$ BP-lowering agent & $12(22.2)$ & $15(30)$ & ns \\
\hline \multicolumn{4}{|l|}{ Cholesterol-lowering agents, $n(\%)$} \\
\hline Atorvastatin $20 \mathrm{mg}$ & $4(7.4)$ & $4(8)$ & \\
\hline Atorvastatin $40 \mathrm{mg}$ & $50(92.6)$ & $30(60)$ & \\
\hline Atorvastatin $80 \mathrm{mg}$ & - & $6(12)$ & \\
\hline Other cholesterol-lowering agents & - & $10(20)$ & \\
\hline$>1$ cholesterol-lowering agent & - & $4(8)$ & 0.03 \\
\hline \multicolumn{4}{|l|}{ Antiplatelets, $n(\%)$} \\
\hline ASA $100 \mathrm{mg}$ & $54(100)$ & $46(92)$ & ns \\
\hline Clopidogrel $75 \mathrm{mg}$ & $2(3.7)$ & $9(18)$ & 0.02 \\
\hline Double antiplatelets (ASA + clopidogrel) & $2(3.7)$ & $5(10)$ & ns \\
\hline
\end{tabular}

BP, blood pressure; ASA, acetylsalicylic acid. ${ }^{\text {a During }} 21$ days.

There were no significant differences regarding the need for more than one BP-lowering agent (22 vs. $30 \%$, ns).

Changes in BP and LDLc levels are summarized in Table 3. BP levels were significantly reduced from a mean of 149.9 to $131 \mathrm{~mm} \mathrm{Hg} \mathrm{(} p<0.001)$, and from 85.5 to $80.4 \mathrm{~mm} \mathrm{Hg} \mathrm{(} p<$ 0.001 ) in the polypill group. LDLc levels were significantly reduced from 109.2 to $79.6 \mathrm{mg} /$ $\mathrm{dL}(p<0.001)$ in the group receiving the cardiovascular polypill. The mean reduction in systolic BP (SBP) was significantly higher in the polypill group than in the conventional treatment group, i.e., 12.1 versus $6.8 \mathrm{~mm} \mathrm{Hg}(p=0.002)$. The goal for $\mathrm{BP}(<140 / 90 \mathrm{~mm} \mathrm{Hg})$ was achieved by 85 and $74 \%$, respectively (ns), and the goal for LDLc ( $\leq 70 \mathrm{mg} / \mathrm{dL})$ was achieved by 41 and $44 \%$, respectively (ns). 


\section{Cerebrovascular Diseases Extra}

\begin{tabular}{l|l}
\hline Cerebrovasc Dis Extra 2020;10:166-173 \\
\hline DOI: 10.1159/000511064 & $\begin{array}{l}\text { @ 2 2020 The Author(s). Published by S. Karger AG, Basel } \\
\text { www.karger.com/cee }\end{array}$ \\
\hline
\end{tabular}

Table 3. BP and LDLc levels

\begin{tabular}{|c|c|c|c|}
\hline & Polypill & $\begin{array}{l}\text { Conventional } \\
\text { treatment }\end{array}$ & $p$ value \\
\hline \multicolumn{4}{|l|}{ SBP, mm Hg } \\
\hline At baseline & $149.9 \pm 12.8$ & $147 \pm 20.3$ & \\
\hline After 90 days & $131 \pm 8.3$ & $135.8 \pm 13.7$ & \\
\hline SBP reduction & $12.1(7.4)$ & $6.8(9.2)$ & 0.002 \\
\hline \multicolumn{4}{|l|}{ DBP, mm Hg } \\
\hline At baseline & $85.5 \pm 8.9$ & $81 \pm 15.9$ & \\
\hline After 90 days & $80.4 \pm 5.8$ & $76.5 \pm 14.1$ & \\
\hline DBP reduction & $5 \pm 11.7$ & $5 \pm 9.2$ & ns \\
\hline BP goal achievement, $n(\%)$ & $46(85.2)$ & $37(74)$ & ns \\
\hline \multicolumn{4}{|l|}{ LDLc, mg/dL } \\
\hline At baseline & $109.2 \pm 27.8$ & $102.2 \pm 30.5$ & \\
\hline After 90 days (mean + SD) & $79.6 \pm 24.9$ & $80.3 \pm 26.7$ & ns \\
\hline LDLc reduction & $24.8 \pm 21.3$ & $17.3 \pm 26.1$ & ns \\
\hline LDLc goal achievement, $n(\%)$ & $22(40.7)$ & $22(44)$ & ns \\
\hline
\end{tabular}

Values denote mean \pm SD unless specified otherwise. BP, blood pressure; SBP, systolic blood pressure; DBP, diastolic blood pressure; LDLc, LDL cholesterol; SD, standard deviation.

There were no recurrences or deaths in the polypill group, and 1 recurrence in the conventional treatment group (ns). In the group receiving the cardiovascular polypill, only 5 patients presented with mild adverse events: cough in 2 (3.7\%), headache in $1(1.9 \%)$, dizziness in $1(1.9 \%)$, and mild epistaxis in $1(1.9 \%)$. In the conventional treatment group, 1 patient suffered an upper gastrointestinal bleeding (2\%) (ns). Ninety-one per cent of the patients were satisfied with the use of the cardiovascular polypill.

Treatment adherence was high in both groups (93 and 88\%, respectively) (ns). Adherence among the patients treated with the polypill in our study was similar to that reported in a previous meta-analysis of RCTs [12] (93 vs. 84.3\%) (ns).

\section{Discussion}

In our study, the effectivity of the cardiovascular polypill was assessed for the first time in stroke prevention in a real-life setting, and compared to a conventional treatment group. Previous clinical trials and a phase IV study support the effectivity of the polypill in improving adherence and controlling VRFs $[13,19]$. However, these studies have some limitations: a low proportion of patients with stroke ( $<15$ and 3\%, respectively); the likelihood of overestimation of adherence; and heterogeneity in the measurement of adherence. Our study contributes to the literature in several ways.

First of all, real-life studies better represent routine practice compared with clinical trials and can provide valuable information about effectivity, safety, and adherence. It is noteworthy that under real-life conditions a significantly higher reduction of SBP was achieved in the group treated with the polypill than in the conventional treatment group. Importantly, hypertension treatment is the most important intervention for cerebrovascular disease prevention. There were some differences in the type and dose of BP-lowering agents between groups, and a higher number of patients in the conventional treatment group received more than one BP-lowering agent (30 vs. $22 \%$; ns). Consequently, we hypothesize that the significant reduction in SBP in the polypill group might be the result of slightly better adherence. 
However, other factors such as the different intensity of BP-lowering agents could have also played a roll.

In addition, LDLc levels were also significantly reduced from baseline. Although the goal of LDL was achieved by 41 and 44\%, respectively (ns), the overall results were better than those in previous studies $[13,19,25]$. This suggests that other factors such as a strict diet, the use of more potent statins, and a longer follow-up may play a role in the control of LDLc levels. Moreover, there were no recurrences or severe adverse events among the patients treated with the polypill. Although the sample was too small to draw conclusions about recurrence, these results support the effectivity of the polypill.

Another issue to consider is the double antithrombotic treatment. In this study, 7 patients received double antithrombotic treatment, $2(3.7 \%)$ in the polypill group and $5(10 \%)$ in the conventional treatment group. It is important to remark that this study was conducted before the publication of the POINT trial [26]. Despite the fact that the cardiovascular polypill only contains ASA, it can be prescribed with clopidogrel in order to simplify the therapeutic scheme from 4 pills (ASA, BP-lowering agent, LDLc-lowering agent, and clopidogrel) to 2 pills (polypill and clopidogrel). This could also be applied to other patients with ischaemic stroke and the need for two antiplatelets, such as patients with carotid or intracranial stents.

Another strength of the study is that adherence was measured with a robust and reproducible scale, the adapted Morisky-Green scale. As previously mentioned, results from adherence trials should be interpreted cautiously as behaviour is significantly changed in RCTs, due to the Hawthorn effect and other factors [19, 27]. However, in this study the polypill showed good results of adherence, similar to those in previous studies, in the real-life setting. A feasible explanation for the lack of significant differences between groups may be attributed to the fact that treatment was started after hospitalization. At that time and during the following months, patients may be more aware of the disabling consequences of stroke recurrence. Consequently, it may occur that differences between groups become significant and more favourable to the use of the polypill after a longer follow-up, as observed in other studies [13].

This study presents some limitations that should be taken into account, such as its relatively small sample size and the heterogeneity of treatment in the conventional treatment group. Although it was not a randomized study, the baseline characteristics were similar in the two groups. Nevertheless, the indication for the use of cardiovascular polypill was decided by a vascular neurologist, taking into account some patients' characteristics. Consequently, the final analysis may have been subject to selection bias. This may limit the generalizability of the results. One can argue that the follow-up of 90 days was short. However, this is the period of highest risk for recurrence after a stroke. Moreover, a longer follow-up may demonstrate better adherence among patients treated with the polypill, as well as better outcomes in the control of VRFs.

\section{Conclusion}

In our experience, the cardiovascular polypill was well tolerated, induced good adherence, and proved to be useful for the prevention of recurrent stroke after hospital discharge, mainly due to better lowering of BP. Regular assessment of BP and LDLc levels is mandatory in order to optimize treatment and prevent vascular events. 


\section{Cerebrovascular Diseases Extra}

\begin{tabular}{|c|c|}
\hline \multicolumn{2}{|c|}{ Cerebrovasc Dis Extra 2020;10:166-173 } \\
\hline DOI: $10.1159 / 000511064$ & $\begin{array}{l}\text { (c) } 2020 \text { The Author(s). Published by S. Karger AG, Basel } \\
\text { www.karger.com/cee }\end{array}$ \\
\hline
\end{tabular}

Ros-Castelló et al.: Real-Life Study of Cardiovascular Polypill Use

\section{Statement of Ethics}

The subjects (or their parents or guardians) have given their informed written consent, and the study protocol was approved by the steering committee of Ramon y Cajal University Hospital (Comité Ético de Investigación Clínica, CEIC 179/18).

\section{Conflict of Interest Statement}

V. Ros-Castelló has received travel grants from Ferrer Laboratories, and J. Masjuan provided consultation to Ferrer Laboratories.

\section{Funding Sources}

Statistical analysis was funded by Grupo Ferrer Internacional, S.A.

\section{Author Contributions}

All authors contributed to the study conception and design. Material preparation and data collection were performed by V. Ros-Castelló, A. Gómez-López, A. Sánchez-Sánchez, and J.L. Chico-García. Analysis was performed by V. Ros-Castelló, E. Natera-Villalba, and A. AlonsoCanovas. The first draft of the manuscript was written by V. Ros-Castelló, E. Natera-Villalba, A. Alonso-Canovas, and J. Masjuan, and all authors commented on previous versions of the manuscript. All authors read and approved the final manuscript.

\section{Data Availability Statement}

The data that support the findings of this study are available from the corresponding author upon reasonable request.

\section{References}

1 Kernan WN, Ovbiagele B, Black HR, Bravata DM, Chimowitz MI, Ezekowitz MD, et al.; American Heart Association Stroke Council, Council on Cardiovascular and Stroke Nursing, Council on Clinical Cardiology, and Council on Peripheral Vascular Disease. Guidelines for the prevention of stroke in patients with stroke and transient ischemic attack: a guideline for healthcare professionals from the American Heart Association/ American Stroke Association. Stroke. 2014 Jul;45(7):2160-236.

2 Arsava EM, Kim GM, Oliveira-Filho J, Gungor L, Noh HJ, Lordelo MJ, et al. Prediction of Early Recurrence after Acute Ischemic Stroke. JAMA Neurol. 2016 Apr;73(4):396-401.

3 González-Juanatey JR, Mostaza JM, Lobos JM, Abarca B, Llisterri JL. A Step Ahead in Secondary Prevention of Cardiovascular Risk. Consensus Document on Clinical Use of the Polypill [in English, Spanish]. Rev Esp Cardiol (Engl Ed). 2016;69(6):547-50.

4 Rodriguez F, Maron DJ, Knowles JW, Virani SS, Lin S, Heidenreich PA. Association of Statin Adherence with Mortality in Patients with Atherosclerotic Cardiovascular Disease. JAMA Cardiol. 2019 Mar;4(3):206-13.

5 Huffman MD, Xavier D, Perel P. Uses of polypills for cardiovascular disease and evidence to date. Lancet. 2017 Mar;389(10073):1055-65.

6 Webster R, Castellano JM, Onuma OK. Putting polypills into practice: challenges and lessons learned. Lancet. 2017 Mar;389(10073):1066-74.

7 Castellano JM, Sanz G, Peñalvo JL, Bansilal S, Fernández-Ortiz A, Alvarez L, et al. A polypill strategy to improve adherence: results from the FOCUS project. J Am Coll Cardiol. 2014 Nov;64(20):2071-82.

\section{Karger'}


8 The Lancet. Polypills: an essential medicine for cardiovascular disease. Lancet. 2017 Mar;389(10073):984.

9 Roy A, Naik N, Srinath Reddy K. Strengths and Limitations of Using the Polypill in Cardiovascular Prevention. Curr Cardiol Rep. 2017 May;19(5):45.

10 Patel A, Cass A, Peiris D, Usherwood T, Brown A, Jan S, et al.; Kanyini Guidelines Adherence with the Polypill (Kanyini GAP) Collaboration. A pragmatic randomized trial of a polypill-based strategy to improve use of indicated preventive treatments in people at high cardiovascular disease risk. Eur J Prev Cardiol. 2015 Jul;22(7): 920-30.

11 Selak V, Elley CR, Bullen C, Crengle S, Wadham A, Rafter N, et al. Effect of fixed dose combination treatment on adherence and risk factor control among patients at high risk of cardiovascular disease: randomised controlled trial in primary care. BMJ. 2014 May;348(may27 11):g3318.

12 Thom S, Poulter N, Field J, Patel A, Prabhakaran D, Stanton A, et al.; UMPIRE Collaborative Group. Effects of a fixed-dose combination strategy on adherence and risk factors in patients with or at high risk of CVD: the UMPIRE randomized clinical trial. JAMA. 2013 Sep;310(9):918-29.

13 Webster R, Patel A, Selak V, Billot L, Bots ML, Brown A, et al. Effectiveness of fixed dose combination medication ('polypills') compared with usual care in patients with cardiovascular disease or at high risk: a prospective, individual patient data meta-analysis of 3140 patients in six countries. Int J Cardiol. 2016 Feb; 205:147-56

14 Athyros VG, Papageorgiou AA, Mercouris BR, Athyrou VV, Symeonidis AN, Basayannis EO, et al. Treatment with atorvastatin to the National Cholesterol Educational Program goal versus 'usual' care in secondary coronary heart disease prevention. The GREek Atorvastatin and Coronary-heart-disease Evaluation (GREACE) study. Curr Med Res Opin. 2002;18:220-8.

15 Cleland JG, Erhardt L, Hall AS, Winter C, Ball SG. Validation of primary and secondary outcomes and classification of mode of death among patients with clinical evidence of heart failure after a myocardial infarction: a report from the Acute Infarction Ramipril Efficacy (AIRE) Study Investigators. J Cardiovasc Pharmacol. 1993; 22 Suppl 9:S22-7.

16 Effect of ramipril on mortality and morbidity of survivors of acute myocardial infarction with clinical evidence of heart failure. The Acute Infarction Ramipril Efficacy (AIRE) Study Investigators. Lancet.1993 Oct;342(8875): 821-8.

17 Tamargo J, Castellano JM, Fuster V. The Fuster-CNIC-Ferrer Cardiovascular Polypill: a polypill for secondary cardiovascular prevention. Int J Cardiol. 2015 Dec;201 Suppl 1:S15-22.

18 Masjuan J, Gállego J, Aguilera JM, Arenillas JF, Castellanos M, Díaz F, et al. Use of cardiovascular polypills for the secondary prevention of cerebrovascular disease [in English, Spanish]. Neurologia. 2018 [Online ahead of print].

19 Castellano JM, Verdejo J, Ocampo S, Rios MM, Gómez-Álvarez E, Borrayo G, et al.; SORS Investigators. Clinical Effectiveness of the Cardiovascular Polypill in a Real-Life Setting in Patients with Cardiovascular Risk: the SORS Study. Arch Med Res. 2019 Jan;50(1):31-40.

20 Lyden P, Brott T, Tilley B, Welch KM, Mascha EJ, Levine S, et al.; NINDS TPA Stroke Study Group. Improved reliability of the NIH Stroke Scale using video training. Stroke. 1994 Nov;25(11):2220-6.

21 Adams HP Jr, Bendixen BH, Kappelle LJ, Biller J, Love BB, Gordon DL, et al. Classification of subtype of acute ischemic stroke. Definitions for use in a multicenter clinical trial. TOAST. Trial of Org 10172 in Acute Stroke Treatment. Stroke. 1993 Jan;24(1):35-41.

22 Piepoli MF, Hoes AW, Agewall S, Albus C, Brotons C, Catapano AL, et al.; ESC Scientific Document Group. 2016 European Guidelines on cardiovascular disease prevention in clinical practice: The Sixth Joint Task Force of the European Society of Cardiology and Other Societies on Cardiovascular Disease Prevention in Clinical Practice (constituted by representatives of 10 societies and by invited experts)Developed with the special contribution of the European Association for Cardiovascular Prevention \& Rehabilitation (EACPR). Eur Heart J. 2016 Aug;37(29):2315-81.

23 Val Jiménez A, Amorós Ballestero G, Martínez Visa P, Fernández Ferré ML, León Sanromà M. Descriptive study of patient compliance in pharmacologic antihypertensive treatment and validation of the Morisky and Green test [in Spanish]. Aten Primaria. 1992 Oct;10(5):767-70.

24 Bharmal M, Payne K, Atkinson MJ, Desrosiers MP, Morisky DE, Gemmen E. Validation of an abbreviated Treatment Satisfaction Questionnaire for Medication (TSQM-9) among patients on antihypertensive medications. Health Qual Life Outcomes. 2009 Apr;7(1):36.

25 Amarenco P, Lavallée PC, Monteiro Tavares L, Labreuche J, Albers GW, Abboud H, et al.; TIAregistry.org Investigators. Five-year risk of stroke after TIA or minor ischemic stroke. N Engl J Med. 2018 Jun;378(23):2182-90.

26 Johnston SC, Easton JD, Farrant M, Barsan W, Conwit RA, Elm JJ, et al.; Clinical Research Collaboration, Neurological Emergencies Treatment Trials Network, and the POINT Investigators. Clopidogrel and Aspirin in Acute Ischemic Stroke and High-Risk TIA. N Engl J Med. 2018 Jul;379(3):215-25.

27 World Health Organisation. Adherence to Long-Term Therapies. Evidence for Action. Geneva: WHO; 2003. 